ФУНКЦИОНИРОВАНИЕ САНАТОРНО-КУРОРТНОГО КОМПЛЕКСА РЕСПУБЛИКИ КРЫМ В ПЕРИОД ПАНДЕМИИ COVID-19

Апатова Н. В., Бакуменко М. А., Титаренко Д. В.

\begin{abstract}
Крымский федеральный университет имени В.И. Вернадского, Симферополь, Российская Федерация

E-mail: apatova@list.ru

В статье проведён анализ функционирования санаторно-курортной отрасли Республики Крым и проблем, возникших в связи с развитием пандемии COVID-19. Отмечена дифференциация данных проблем для различных категорий коллективных средств размещения. Определена совокупность мероприятий, способствующих предотвращению негативных последствий сложившейся ситуации и уменьшению рисков последствий пандемии. Обоснована необходимость развития медицинской базы санаторно-курортных учреждений Республики Крым. Проанализирован инструментарий Интернетмаркетинга, который способствует повышению конкурентоспособности коллективных средств размещения Республики Крым. Отмечена целесообразность комплексного применения инструментария Интернет-маркетинга для достижения синергетического эффекта.

Ключевые слова: санаторно-курортная отрасль, коллективное средство размещения, Республика Крым, пандемия COVID-19, конкурентоспособность, безопасность, риск, Интернет-маркетинг.
\end{abstract}

\title{
ВВЕДЕНИЕ
}

Пандемия COVID-19 нанесла огромный ущерб национальным экономикам всего мира, в том числе экономике Российской Федерации и ее регионам. Последствия пандемии ещё предстоит оценить в перспективе. Одной из отраслей, которой был нанесён значительный урон, стала санаторно-курортная отрасль. Ползикова Е. В. и Юрченко А. А. отмечают, что «...туристская отрасль станет самой пострадавшей в сложившейся ситуации» $[1$, с. 99]. Согласно прогнозу Всемирного совета по путешествиям и туризму (англ., World Travel and Tourism Council), в 2020 году число путешествий в мире может сократиться на четверть по сравнению с предыдущим годом [2, с. 81]. Пандемия COVID-19 привела в апреле 2020 года к временному исчезновению туристских потоков [3]. По оценкам экспертов, в марте 2020 года закрытие туристического сообщения с Китаем привело к убыткам российских туроператоров в объеме 590 млн рублей $[4$, с. 66].

Санаторно-курортная отрасль является одной из основных для Республики Крым. В апреле-июне 2020 года коллективные средства размещения Республики Крым практически не функционировали и столкнулись со значительными финансовыми проблемами, приведшими в ряде случаев к сокращению персонала предприятий и закрытию ряда коллективных средств размещения.

С 1 июля 2020 года в Республике Крым открыт курортный сезон и смягчены требования по обеспечению безопасности в период пандемии. В настоящее время перед Правительством стоит сложная задача. С одной стороны, позволить предприятиям курортной сферы получать доход, а с другой стороны, удержать ситуацию с распространением пандемии на допустимом уровне. Сейчас, как никогда, 
санаторно-курортная отрасль Республики Крым нуждается в грамотном управлении и контроле.

Проблемы развития санаторно-курортной сферы Республики Крым привлекли к себе внимание значительного числа представителей науки. Можно назвать работы Дышлового И. Н. [5], Оборина М. С. [6], Узунова Ф. В. [7], Швец И. Ю. [8], Яковенко И. М. [9] и др. Анализу влияния пандемии COVID-19 на сферу туризма в России и её отдельных регионах посвящены работы Алейновой А. А. [10], Дородной А. В., Омельченко А. Д. [2], Лингурян Н. В., Калинкиной С. А. [4] Ползиковой Е. В., Юрченко А. А. [1], Симонян Г. А., Сарян А. А. [3] и др.

Распространение COVID-19 привело к возникновению новых проблем и трудностей в санаторно-курортной отрасли Республики Крым. Данные проблемы нуждаются в тщательном анализе и постоянном мониторинге, а также в разработке и реализации совокупности мероприятий, направленных на улучшение ситуации в отрасли и предотвращения рисков. Вышесказанное обуславливает актуальность выбранной темы исследования.

Цель статьи - на основе анализа функционирования санаторно-курортной отрасли Республики Крым и проблем, обусловленных пандемией COVID-19, сформулировать ряд рекомендаций по предотвращению негативных последствий сложившейся ситуации и уменьшению рисков.

Для достижения поставленной цели были выделены и решены следующие задачи:

1) проанализировать проблемы, возникшие в санаторно-курортной отрасли Республики Крым в связи с развитием пандемии COVID-19;

2) выделить совокупность мероприятий, способствующих предотвращению негативных последствий сложившейся ситуации и уменьшению рисков;

3) проанализировать инструменты Интернет-маркетинга, которые будут способствовать повышению конкурентоспособности коллективных средств размещения Республики Крым.

\section{ОСНОВНОЙ МАТЕРИАЛ}

\section{1. АНАЛИЗ ФУНКЦИОНИРОВАНИЯ САНАТОРНО-КУРОРТНОГО КОМПЛЕКСА РЕСПУБЛИКИ КРЫМ И ПРОБЛЕМ, ОБУСЛОВЛЕННЫХ ПАНДЕМИЕЙ COVID-19}

Зарождение рекреационной деятельности как вида экономической активности на территории Крымского полуострова относится к началу XIX века [9]. В настоящее время данный вид экономической деятельности является одним из основных для региона. Оборин М. С. называет Республику Крым «... важнейшим центром развития туристско-рекреационной деятельности и курортного дела» в Российской Федерации [6, с. 120]. Санаторно-курортная отрасль Республики Крым «...наполняет бюджеты всех уровней, стимулирует рост смежных отраслей экономики и обеспечивает значительную часть населения рабочими местами» [7, с. 150].

Если развивать санаторно-курортную отрасль Республики Крым в правильном направлении, то можно реализовать большой потенциал и значительные 
перспективы. Как отмечено в работе Дышлового И. Н., «стратегической целью развития Республики Крым является формирование современного международного туристского центра» $[5$, с. 51$]$.

Весной 2020 года санаторно-курортная отрасль Республики Крым столкнулась с дополнительными трудностями, обусловленными распространением в Российской Федерации пандемии COVID-19. В связи с угрозой распространения COVID-19 на территории Республики Крым с 28 марта 2020 года коллективные средства размещения региона могли принимать гостей лишь в том случае, если у них была оформлена официальная служебная командировка в соответствующий населенный пункт. Коллективным средствам размещения было запрещено принимать гостей, прибывших на территорию полуострова с другими целями, до 1 июня 2020 года. Далее этот период был продлён ещё на 1 месяц. С 15 июня 2020 года отелям и санаториям Республики Крым было разрешено принимать только крымчан. И лишь с 1 июля 2020 года был официально открыт курортный сезон и сняты ограничения на приём гостей при соблюдении определенных правил безопасности, ознакомиться с которыми можно на сайте Роспотребнадзора Российской Федерации и которые изложены в документе [11].

Возникшая ситуация в апреле-июне 2020 года привела к почти полной остановке работы отелей и санаториев полуострова, которые столкнулись со значительными финансовыми проблемами, обусловленными следующими обстоятельствами:

- в период низкого сезона загрузка отелей и санаториев полуострова была невысокая и, соответственно, доходы тоже;

- предприятия курортной сферы рассчитывали на получение стабильного дохода с мая 2020 года;

- начался процесс отмены оплаченных броней;

- у предприятий курортной сферы не было средств на выплату заработной платы, а также средств для расчётов с поставщиками и подрядчиками;

- возникшая ситуация характеризовалась значительной степенью неопределённости: было неясно, когда будут сняты введённые ограничения.

Возникшие финансовые проблемы привели к сокращению ряда сотрудников предприятий курортной сферы, а также к закрытию части коллективных средств размещения Республики Крым.

С 1 июля 2020 года был открыт курортный сезон. Спрос на услуги отелей и санаториев Республики Крым в июле 2020 года очень высокий, что обусловлено недоступностью для россиян зарубежных курортов. Несмотря на сложившуюся благоприятную ситуацию со спросом на услуги коллективных средств размещения Республики Крым в данной сфере возник ряд существенных проблем. Эти проблемы различны для разных категорий коллективных средств размещения.

В настоящее время крымские отели премиум-сегмента характеризуются высоким спросом, и объекты размещения даже повысили цены на свои услуги в период высокого сезона (на 50-100 \%) [12]. Данное повышение цен обусловлено ажиотажным спросом. Так, например, самый недорогой номер на 2 человек в Mriya Resort \& Spa (г. Ялта) в июле 2020 года стоил почти 40 тыс. руб. в сутки. А 
посещаемость сайтов некоторых отелей данной категории по сравнению с аналогичным периодом прошлого года возросла почти в три раза.

Такой ажиотаж на отдых в отелях премиум-сегмента Республики Крым привёл к возникновению ряда проблем:

- проблема обеспечения безопасности людей и соблюдения правил Роспотребнадзора в связи с пандемией COVID-19 как сотрудниками отелей, так и гостями (за нарушение данных правил отель может быть закрыт на достаточно продолжительный период времени);

- проблема качества обслуживания - за время карантина некоторые предприятия курортной сферы были вынуждены сократить часть персонала и теперь столкнулись с проблемой нехватки высококвалифицированных специалистов (официантов, поваров и т. д.). Высокая нагрузка на персонал может приводить к снижению качества обслуживания;

- проблема организации досуга гостей в условиях пандемии;

- проблема угрозы репутации. Гости отелей премиум-сегмента ожидают от отелей крымского полуострова комфорта и высокого качества обслуживания. В случае высокой загрузки отелей и нехватки персонала может возникнуть ситуация снижения качества обслуживания и, соответственно, угроза ухудшения репутации отеля и потери клиентов. Кроме того, как отмечено в [12], не все отели Республики Крым премиум сегмента могут обеспечить требуемое качество обслуживания.

Больше всего от пандемии COVID-19 пострадали коллективные средства размещения бюджетной категории (например, хостелы):

- по правилам Роспотребнадзора запрещено размещать в одной комнате более 2 человек;

- стоимость проживания в объектах данной категории должна быть невысокой;

- необходимо обеспечивать безопасность гостей, что связано с дополнительными финансовыми затратами, которые являются существенными для коллективных средств размещения данной категории [13].

То есть для некоторых коллективных средств размещения полуострова даже после открытия курортного сезона финансовые проблемы остаются актуальными. Также можно отметить, что финансовая успешность курортного сезона 2020 года для отелей и санаториев Крымского полуострова будет во многом зависеть от развития ситуации с пандемией COVID-19. И здесь сложно что-либо прогнозировать, можно лишь разрабатывать сценарии.

В целом для коллективных средств размещения Республики Крым любых категорий в настоящее время существует ряд общих проблем, обусловленных пандемией:

- проблема неопределённости. В связи с распространением COVID-19 благоприятная ситуация со спросом может измениться в худшую сторону в любой момент;

- открытие зарубежных курортов для россиян может снизить спрос на услуги коллективных средств размещения крымского региона;

- проблема обеспечения безопасности сотрудников и гостей; 
- проблема организации досуга гостей;

- проблема выполнения всех требований Роспотребнадзора в связи с пандемией COVID-19;

- проблема создания комфортных условий для отдыхающих.

Также следует заметить, что затраты коллективных средств размещения на выполнение рекомендаций Роспотребнадзора, которые являются достаточно существенными, войдут в стоимость проживания и лягут на плечи гостей курортов [12]. Но в сложившейся ситуации нет другого решения.

\section{2. МЕРОПРИЯТИЯ ПО ПРЕДОТВРАЩЕНИЮ НЕГАТИВНЫХ ПОСЛЕДСТВИЙ СЛОЖИВШЕЙСЯ СИТУАЦИИ И УМЕНЫШЕНИЮ РИСКОВ}

Как отмечалось ранее, одной из проблем для предприятий санаторно-курортного комплекса Республики Крым является проблема неопределённости. Успешное проведение курортного сезона будет зависеть от развития ситуации с распространением COVID-19. В Республике Крым почти ежедневно регистрируют (в разных регионах) случаи заражения новой короновирусной инфекцией, несмотря на то что температурный режим летних месяцев в Крыму не является благоприятным для распространения данного вируса.

Положительный исход данной ситуации будет зависеть от многих лиц: сотрудников отелей и санаториев, гостей полуострова, а также населения Республики Крым. Коллективные средства размещения Республики Крым должны приложить максимум усилий для неукоснительного соблюдения всех правил Роспотребнадзора, а также должны контролировать выполнение правил безопасного проживания гостями полуострова.

Ещё одной важной проблемой является проблема соблюдения правил безопасности в связи с распространением COVID-19 населением полуострова, в том числе в общественных местах (городском транспорте, торговых объектах и т. д.). В настоящее время Правительство Республики Крым отменило штрафы за несоблюдение данных правил в общественных местах, оставив это на совести граждан. Крымчане должны понимать, что ухудшение ситуации с COVID-19 в регионе приведет к провалу курортного сезона, росту безработицы и потере доходов. Известно, что летние месяцы являются для многих крымчан возможностью заработать средства на целый год.

В работе [10, с. 15] отмечается тенденция изменения психологии и поведения потребителей туристических услуг, которая с течением времени скорее всего только усилится. Так, при выборе мест отдыха и объектов размещения значительное внимание будет уделяться вопросам безопасности, а также качества и доступности медицинских услуг.

В то же время, как показали исследования, значительная часть россиян не готова отказаться от отдыха и туристических поездок. В статье [1, с. 99-100] представлены результаты социологического опроса, проведённого специалистами поискового сервиса Aviasales. Данный опрос был направлен на выявление протяжённости временного интервала, в течение которого граждане Российской Федерации могут воздержаться от отпуска (поездок на отдых). Было выявлено, что без отпуска 1 год 
могут провести 50 \% опрошенных, полгода - 25\%, 3 месяца $-11 \%, 1$ месяц - $14 \%$. Приведённые данные позволяют надеяться, что спрос на услуги туристической индустрии всё же сохранится. И задача коллективных средств размещения Республики Крым заключается в проведении правильной маркетинговой политики, направленной на завоевание новых и удержание старых клиентов, а также на повышение качества предоставляемых услуг.

Отелям и санаториям Республики Крым необходимо приложить значительные усилия (не только организационного, но и финансового характера), чтобы обеспечить комфортное пребывание на своей территории отдыхающих. Это очень важно, несмотря на значительный спрос на услуги коллективных средств размещения полуострова в настоящее время. Предприятиям курортной сферы необходимо понимать, что сложившаяся ситуация со спросом может очень быстро измениться за счёт открытия зарубежных курортов для граждан Российской Федерации. В настоящее время у крымских отелей и санаториев есть прекрасная возможность завоевать доверие гостей и превратить их в своих постоянных клиентов. О необходимости формирования конкурентных преимуществ санаторно-курортных учреждений на длительную перспективу говорится в монографии [8].

Также здесь необходимо вести сбалансированную ценовую политику, чтобы цена услуги все же соответствовала её качеству и чтобы в итоге у отдыхающих не возникло негативное восприятие коллективного средства размещения, которое, как известно, может быть отражено в Интернет и явиться антирекламой. И, соответственно, гость отеля или санатория, который остался доволен качеством обслуживания и стоимостью услуги, может стать бесплатным источником рекламы для коллективного средства размещения и вернуться обратно на следующий год.

Тем более, что Крымский полуостров является уникальным местом для отдыха и обладает необыкновенно красивой природой и лечебным климатом, а также большим количеством достопримечательностей. Как показали недавние социологические опросы, «...по критерию «цена/качество» крымские курорты имеют невысокую оценку по мнению потребителей туристических услуг» [14, с. 213].

Пандемия COVID-19 привела к снижению доходов значительной части россиян и, следовательно, уменьшила их возможности на летний отдых у моря. Санатории Республики Крым целесообразно загрузить частично за счёт бюджетных средств. Бюджетные учреждения и предприятия Российской Федерации могут выкупить для своих сотрудников путёвки на отдых и лечение в санаториях Крыма. В санаторном лечении сейчас нуждаются учителя общеобразовательных школ и медицинские работники, которым пришлось работать в достаточно сложных условиях в период развития пандемии COVID-19 в России (в апреле-июне 2020 года). О необходимости субсидирования отдыха для социально незащищённых слоёв населения говорится в работе [1, с. 100].

Ряд предприятий санаторно-курортного комплекса Республики Крым нуждается в государственной поддержке, которая может быть предоставлена в виде льгот в сфере налогообложения. Как отмечалось ранее, некоторые коллективные средства размещения полуострова, несмотря на открытие курортного сезона, находятся в достаточно трудном финансовом положении. Эта ситуация требует от Правительства 
глубокого анализа и определенных мер поддержки предпринимателей. Эти меры должны быть эффективными. Как отмечено в работе [1, с. 99], разработанные ранее (в начале развития пандемии) меры Правительства в данном направлении явились нерезультативными.

От пандемии COVID-19 сильно пострадал конференц-сервис. В настоящее время проведение массовых мероприятий (в том числе конференций и симпозиумов) запрещено. А как известно, отели Республики Крым располагают достаточно хорошей инфраструктурой для предоставления услуг конференц-сервиса. По состоянию на начало 2018 года в Республике Крым услуги конференц-сервиса предоставляло 71 коллективное средство размещения. На территории данных объектов было размещено 170 залов различной вместительностью (от 50 чел. до 1800 чел.) $[14$, с. 217].

Для ряда предприятий санаторно-курортной отрасли Республики Крым характерными являются «старые» проблемы, которые обусловлены неразвитостью материально-технической базы, низким уровнем квалификации персонала и, соответственно, достаточно низким качеством обслуживания [6, с. 129; 7, с. 151]. Стоимость предоставления санаторно-оздоровительных услуг является относительно высокой, что обусловлено значительной сезонностью работы санаторно-курортных учреждений Республики Крым [6, с. 129].

Можно отметить, что пандемия COVID-19 уменьшила возможности санаториев Республики Крым по улучшению их материально-технической базы за счёт собственных средств. Санаторно-курортные учреждения, находящиеся в государственной собственности, остро нуждаются в бюджетных инвестициях, направленных на улучшение их материально-технической базы. Также, как отмечено в $[1$, c. 100$]$, целесообразной является государственная поддержка частных инвестиционных инициатив в санаторно-курортной отрасли.

Как было отмечено ранее, в связи со сложившейся ситуацией с распространением пандемии COVID-19 при выборе мест отдыха и объектов размещения значительное внимание будет уделяться вопросам безопасности, а также качества и доступности медицинских услуг. Данный факт говорит о необходимости развития медицинской базы санаторно-курортных учреждений Республики Крым.

Как отмечено в работе [14, с. 214], на территории Республики Крым в 2016 году лишь $18,8 \%$ санаторно-курортных учреждений предоставляли услуги лечения (санатории, гостиницы с медцентром, пансионаты с лечением). Данная цифра может быть значительно выше, что будет способствовать круглогодичной работе данных учреждений и повышению их средней загрузки. Так, например, «... в период осени 2016 г. - весны 2017 г. в Республике Крым в круглогодичном режиме функционировали 83,3\% гостиниц с медцентром (и только 54,6\% гостиниц без медцентра), 51,7 \% детских санаториев, 36,8 \% пансионатов с лечением (и только $11,5 \%$ пансионатов без лечения), 48,3\% санаториев» [14, с. 214]. 


\section{3. ПОВЫШЕНИЕ КОНКУРЕНТОСПОСОБНОСТИ КОЛЛЕКТИВНЫХ СРЕДСТВ РАЗМЕЩЕНИЯ РЕСПУБЛИКИ КРЫМ С ПОМОЩЬЮ ИНТЕРНЕТ-МАРКЕТИНГА}

Обеспечение конкурентоспособности любого предприятия, в том числе предприятия санаторно-курортной отрасли, в настоящее время не представляется возможным без эффективной маркетинговой политики. Как отмечает Оборин М. С. [6, с. 129], проблема сезонности функционирования многих предприятий санаторнокурортного комплекса Республики Крым во многом обусловлена неверной маркетинговой политикой данных хозяйствующих субъектов.

Также в работе [6] отмечена необходимость создания «... конкурентного санаторно-курортного продукта на российском и мировом рынках, способного удовлетворить разнообразные туристские и лечебно-оздоровительные потребности населения» [6, с. 129]. В процессе создания конкурентного санаторно-курортного продукта не последняя роль принадлежит комплексу маркетинговых мероприятий, проводимых в информационно-коммуникационной сети Интернет.

Как показала практика, коллективные средства размещения Республики Крым, которые в период апреля-июня 2020 года продолжили маркетинговую деятельность в Интернет (наполняли социальные сети, проводили контекстную рекламу и т. д.), после снятия ограничений и открытия курортного сезона 2020 года оказались в достаточно выгодном положении и даже смогли повысить цены на предоставляемые услуги.

Особенностями Интернет-маркетинга являются высокая степень персонализации, интерактивность, информативность, экономичность и оперативность [15, с. 45-46]. Инструментарий Интернет-маркетинга предоставляет специалистам ряд существенных преимуществ: доступ к огромной базе данных, недоступной для офлайн-маркетологов (сервисы аналитики, коллтрекинг, сервисы почтовых рассылок и др.); значительное сокращение расходов на рекламу благодаря направлению ресурсов на каналы продвижения с максимальной отдачей [16, с. 185].

Интернет-маркетинг должен быть связан с офлайн-маркетингом. Основными инструментами Интернет-маркетинга являются поисковая оптимизация (англ., Search Engine Optimization, SEO), контекстная реклама, маркетинг в социальных сетях (англ., Social Media Marketing, SMM), в том числе таргетированная реклама, Еmail-маркетинг, медийная (баннерная) реклама, сайты-агрегаторы, видеореклама $[16$, c. 185$]$.

Эффективное применение инструментария Интернет-маркетинга возможно только в комплексе, за счёт чего достигается значительный синергетический эффект [17, с. 15$]$.

В работе [18] было проанализировано присутствие в социальных сетях коллективных средств размещения премиум-сегмента Республики Крым, прошедших классификацию с присвоением категории «4 звезды» либо «5 звёзд». Исследование, представленное в [18], показало, что отели Республики Крым с более высокой ценовой политикой прилагают больше маркетинговых усилий (в том числе в социальных сетях) при продвижении продукта на рынок.

В Республике Крым более 80 \% коллективных средств размещения премиумсегмента проводят работу в социальных сетях. Среди коллективных средств 
размещения премиум сегмента Республики Крым наиболее популярны следующие социальные сети Facebook, Instagram и ВКонтакте [18].

Для эффективной работы в социальных сетях предприятиям санаторнокурортного комплекса Республики Крым необходимо [18]: ориентироваться на социальные сети, в которых расположена целевая аудитория; проводить работу в социальных сетях на методичной и регулярной основе; осуществлять постоянный мониторинг конкурентов; разрабатывать стратегию продвижения; составлять чёткий контент-план, предполагающий создание качественных публикационных материалов; выделять средства на таргетированную рекламу с формой оплаты «за каждый клик на объявление»; осуществлять взаимовыгодное сотрудничество с другими сообществами социальных сетей; избегать запрещённых инструментов продвижения; эффективно работать с аудиторией; проводить анализ эффективности работы в социальных сетях; применять релевантные инструменты поисковой оптимизации; активно привлекать новую аудиторию в социальные сети; использовать современные информационные технологии; знать и учитывать правовые аспекты. Соблюдение данных рекомендаций в практической деятельности коллективных средств размещения Республики Крым будет способствовать повышению эффективности работы в социальных сетях и улучшению корпоративной репутации.

\section{ВЫвОДЫ}

По итогам проведённого исследования можно сделать следующие основные выводы:

1. Одной из отраслей, которой был нанесён значительный урон в связи с распространением пандемии COVID-19, стала санаторно-курортная отрасль. Несмотря на сложившуюся благоприятную ситуацию со спросом на услуги коллективных средств размещения Республики Крым после открытия курортного сезона 2020 года, в санаторно-курортной отрасли возник ряд существенных проблем, которые различны для разных категорий коллективных средств размещения. Для ряда коллективных средств размещения полуострова даже после открытия курортного сезона финансовые проблемы остаются актуальными.

2. Для коллективных средств размещения Республики Крым любых категорий в настоящее время существует ряд общих проблем, обусловленных пандемией: проблема неопределённости; возможность снижения спроса благодаря открытию зарубежных курортов; проблема обеспечения безопасности сотрудников и гостей; проблема организации досуга гостей; проблема выполнения всех требований Роспотребнадзора в связи с пандемией COVID-19; проблема создания комфортных условий для отдыхающих.

3. Успешное проведение в Республике Крым курортного сезона 2020 года будет зависеть от развития ситуации с распространением COVID-19. Коллективные средства размещения Республики Крым должны приложить максимум усилий для неукоснительного соблюдения всех правил Роспотребнадзора, а также должны контролировать выполнение правил безопасного проживания гостями полуострова. 
4. Значительная часть россиян не готова отказаться от отдыха и туристических поездок, что позволяет надеяться на наличие спроса на услуги туристической индустрии. Задача коллективных средств размещения Республики Крым заключается в проведении правильной маркетинговой политики, направленной на завоевание новых и удержание старых клиентов, а также на повышение качества предоставляемых услуг.

5. Предприятиям санаторно-курортного комплекса Республики Крым необходимо вести сбалансированную ценовую политику, чтобы цена услуги соответствовала её качеству.

6. Санатории Республики Крым целесообразно загрузить частично за счёт бюджетных средств. Ряд предприятий санаторно-курортного комплекса Республики Крым нуждается в государственной поддержке, которая может быть предоставлена в виде льгот в сфере налогообложения. Санаторно-курортные учреждения, находящиеся в государственной собственности, остро нуждаются в бюджетных инвестициях, направленных на улучшение их материально-технической базы. Также целесообразной является государственная поддержка частных инвестиционных инициатив в санаторно-курортной отрасли.

7. Развитие медицинской базы санаторно-курортных учреждений Республики Крым является острой необходимостью и будет способствовать круглогодичной работе данных учреждений и повышению их средней загрузки.

8. В процессе создания конкурентного санаторно-курортного продукта важная роль принадлежит комплексу маркетинговых мероприятий, проводимых в информационно-коммуникационной сети Интернет. Эффективное применение инструментария Интернет-маркетинга возможно только в комплексе, за счёт чего достигается значительный синергетический эффект.

Перспективой исследований в данном направлении видим дальнейший мониторинг ситуации, сложившейся в санаторно-курортном комплексе Республики Крым в связи с пандемией COVID-19.

\section{Список литературы}

1. 1. Ползикова Е. В., Юрченко А. А. Анализ влияния пандемии на сферу авиаперевозок и туризм в России // Научный вестник Южного института менеджмента. 2020. № 2. С. 98-103.

2. Дородная А. В., Омельченко А. Д. Анализ туристских предложений астраханцев в период летнего отдыха (на примере ТК «Континенталь») // Прорывные научные исследования: проблемы, пределы и возможности: Сборник статей по итогам Международной научно-практической конференции (Новосибирск, 03 апреля 2020 г.). Стерлитамак: АМИ, 2020. С. 79-82.

3. Симонян Г. А., Сарян А. А. О влиянии пандемии коронавируса на туризм // Современная научная мысль. 2020. № 2. С. 158-164.

4. Лингурян Н. В., Калинкина С. А. Туризм в России в период и после пандемии // Прорывные экономические реформы в условиях риска и неопределенности: сборник статей по итогам Международной научно-практической конференции (Казань, 23 мая 2020 г.). Стерлитамак: АМИ, 2020. С. $65-66$.

5. Дышловой И. Н. Состояние, проблемы и перспективы развития санаторно-курортной и туристской отрасли Республики Крым // Современные проблемы сервиса и туризма. 2015. № 1. Т. 9. С. 51-59.

6. Оборин М. С. Факторы развития рынка санаторно-курортного комплекса Крымского федерального округа // Вестник Дагестанского государственного технического университета. 2015. № 1 (36). C. 120-130. 
7. Узунов Ф. В., Горбатова Е. Ф. Внедрение кластерной модели - решение проблем развития и реформирования рекреационного комплекса в Республике Крым// Международный научный журнал «Символ науки». 2016. № 10-1. С. 150-153.

8. Швец И. Ю. Региональное управление конкурентоспособностью туристических услуг: методология и практика. Симферополь: ЧП Феникс, 2012. 372 с.

9. Яковенко И. М. Эволюция процесса туристско-рекреационного развития Крыма: географический аспект // Культура народов Причерноморья. 2009. № 176. С. 190-194.

10. Алейнова А. А. Индустрия туризма и отдыха Краснодарского края после пандемии (COVID-19) // Современные проблемы и пути их решения в науке, производстве и образовании. 2020. № 9. C. $13-16$.

11. Рекомендации по профилактике новой короновирусной инфекции (COVID-19) в учреждениях, осуществляющих деятельность по предоставлению мест для временного проживания (гостиницы и иные средства размещения). МР 3.1/2.1.0187-20.

12. Отели Черноморского побережья России повысили цены из-за закрытых границ [Электронный pecypc]. URL: https://news.mail.ru/society/42444107/?frommail=1.

13. Чемоданное построение: как будут отдыхать россияне с 1 июля [Электронный pecypc]. URL: https://news.mail.ru/society/42380875/?frommail=10.

14. Бакуменко М. А. О проблемах повышения конкурентоспособности крымского региона как курортной территории // Научный вестник: финансы, банки, инвестиции. 2018. № 4 (45). C. 211-220.

15. Интернет-маркетинг и digital-стратегии. Принципы эффективного использования. Новосибирск: РИЦ НГУ, 2015. 327 с.

16. Бакуменко М. А., Бакуменко А. А. Интернет-маркетинг и обеспечение устойчивого развития предприятия // Устойчивое развитие социально-экономической системы Российской Федерации: сборник трудов XXI Всероссийской научно-практической конференции, г. Симферополь, 14-15 ноября 2019 г. / научн. ред. В. М. Ячменевой; редкол.: Е. Ф. Ячменев, Т. И. Воробец, Р. А. Тимаев. Симферополь: ИТ «АРИАЛ», 2019. С. 184-187.

17. Борисов А. А. Особенности классификации digital-инструментов продвижения товаров и услуг // Вестник Алтайской академии экономики и права. Экономические науки. 2018. № 4. С. 15-21.

18. Бакуменко М. А., Бакуменко А. А. Анализ присутствия в социальных сетях средств размещения премиум-сегмента Республики Крым // Управление экономическими системами. Электронный научный журнал. 2019. № 12 [Электронный ресурс]. URL: http://uecs.ru.

Статья поступила в редакцию 17.07.2020 